\title{
Integrated AI and Innovation Management: The Beginning of a Beautiful Friendship
}

\author{
Nina Bozic Yams, Valerie Richardson, Galina Esther Shubina, Sandor
}

\author{
Albrecht and Daniel Gillblad
}

\author{
" Technological change defines the horizon of our material world as it shapes the \\ limiting conditions of what is possible and what is barely imaginable. It erodes \\ assumptions about the nature of our reality, the "pattern" in which we dwell, \\ and lays open new choices."
}

Shoshana Zuboff

\begin{abstract}
There is a growing consensus around the transformative and innovative power of Artificial Intelligence (AI) technology. AI will transform which products are launched and how new business models will be developed to support them. Despite this, little research exists today that systematically explores how AI will change and support various aspects of innovation management. To address this question, this article proposes a holistic, multi-dimensional AI maturity model that describes the essential conditions and capabilities necessary to integrate AI into current systems, and guides organisations on their journey to AI maturity. It explores how various elements of the innovation management system can be enabled by AI at different maturity stages. Two key experimentation stages are identified, 1) an initial stage that focuses on optimisation and incremental innovation, and 2) a higher maturity stage where AI becomes an enabler of radical innovation. We conclude that AI technologies can be applied to democratise and distribute innovation across organisations.
\end{abstract}

\section{Introduction}

The adoption of Artificial Intelligence (AI) in business is accelerating. According to McKinsey, $58 \%$ of organisations embedded at least one AI capability into a process or product (Cam, 2019). By integrating AI into business holistically across an organisation, it gains the potential to create competitive advantages and strengthen organisational innovation capabilities (Cockburn et al., 2018; Fountaine et al., 2019; Prem, 2019; Raisch \& Krakowski, 2020).

However, very few organisations (including businesses, public sector and NGOs) today have seen widespread adoption of AI (Fountaine et al., 2019), and limited research is currently available on how using AI can support specific challenges related to innovation management (Prem, 2019). Existing models of AI in organisations have not integrated the technical, organisational, and ethical aspects of business, nor have they addressed how AI integration is intertwined with innovation management. According to the authors of this article, the strategic integration of AI and innovation management in organisations go hand-in-hand, mutually complementing and enabling each other. The following questions are thus explored in the article: What does the journey towards trustworthy integrated AI in organisations look like? And second, how could integrating trustworthy AI act as an enabler for innovation management systems?

Traditionally, for complex issues such as sustainability or general-purpose technologies like AI, frameworks are used to create structure and to decompose aspects into specific categories and maturity stages. These frameworks serve an essential role in educating management, creating clarity, improving the ability to act, and accelerating adoption. A number of AI maturity frameworks have been published (see Figure 1) that typically cover specific aspects of AI integration in business, but do not holistically integrate the technical, organisational, and ethical aspects in a comprehensive way. In this paper, we propose an AI Innovation Maturity Index (AIMI) as an attempt to rectify this.

We consider different elements of innovation management systems according to the international standard ISO 56002, and examples of how AI 


\section{Integrated AI and Innovation Management: The Beginning of a Beautiful Friendship Nina Bozic Yams, Valerie Richardson, Galina Esther Shubina, Sandor Albrecht and Daniel Gillblad}

technologies could be used to support and augment them. These were explored regarding how to increase organisational innovation capability. The paper focuses specifically on the application of AI at various levels of AI maturity and its implications for democratising and distributing innovation, increasing diversity, interdisciplinary and cross-functional collaboration, building a learning organisation, strengthening capacity for foresight activities, and embracing uncertainty in organisations.

\section{Theoretical Background}

\section{AI and organisations: current practice and challenges} Many large multinational consulting firms tout significant potential for AI technologies. At the same time, AI is still in an early commercialisation phase, with only $8 \%$ of firms today seeing widespread AI adoption across the organisation (Fountaine et al., 2019). Limited empirical work has been published on challenges related specifically to AI and innovation management (Prem, 2019). A key pattern in adopting AI symbolises a separation between incremental use cases that optimise the existing business processes, and products along with transformational use cases that shift an organisation, its products and sometimes the market. Influenced by the "innovation and ambition matrix" (Nagji and Tuff, 2012), and inspired by the notions defined by Laszlo and Zhexembayeva (2011) in their work on "embedded sustainability", we refer to the two ends of the AI spectrum as bolt-on and integrated AI.

Bolt-on $A I$ is implemented in existing business processes and products through projects in noncritical areas, which are relatively independent of other parts. It focuses predominantly on optimising existing processes, risk management, and short-term return on investment, to enable incremental innovation of the existing business. In contrast, integrated $A I$ considers a company's core domain area and becomes deeply integrated with the overall organisational purpose and strategy. It is long-term oriented and strategic, focusing on a company's wider ecosystem, with an aim to create value across a broader market. The latter type of AI sets the groundwork for transformational or radical innovation.
Larger business organisations struggle with broader AI integration partly due to cultural and organisational barriers (Fountaine et al., 2019). Many large, rigid, hierarchical systems have low levels of flexibility and adaptability where employees with innovation competence and mindset become limited to specific parts of an organisation, rather than spread effectively across the system. Managers rarely understand that while they need cutting-edge technology, the ways they align it with their organisation's culture, structure, and ways of working is equally important (Fountaine et al., 2019). Unsurprisingly, some studies show that start-ups have a vital role to play in both the application and deployment of AI innovations in companies as they are considered to be the leaders and main competence carriers in AI technology (Prem, 2019).

Fountaine et al. (2019) suggest that large organisations need to go through various shifts to enable the scaling up of AI, such as moving: 1) from silos towards more interdisciplinary collaboration, 2) from experiencebased, leader-driven decision making to data-driven decision making at the front line, and 3) from rigid and risk-averse to an agile, experimental and adaptable mindset and ways of working (Fountaine et al., 2019).

\section{Existing AI maturity frameworks}

The 'maturity model' concept was introduced in 1986 by Carnegie Mellon with its "capability maturity model" (Paulk, 2009). Since then, a widespread adoption of maturity models has taken place for process optimisation, innovation management, and digital transformation. Such maturity models are most prevalent in domains that are inherently complex, requiring a systematic, and structured approach. More recently, digital maturity models (DMMs) have proliferated, driven in part by "Industry 4.0" (Teichert, 2019). Just as Teichert found with the early DMMs, in this research we have seen that existing AI-specific models are developed primarily by practitioners rather than in academia.

While a complete review of AI frameworks is outside the scope of this article, in Figure 1 thirteen representative examples are shown. Some of the top patterns found in existing frameworks include: 


\section{Integrated AI and Innovation Management: The Beginning of a Beautiful Friendship Nina Bozic Yams, Valerie Richardson, Galina Esther Shubina, Sandor Albrecht and Daniel Gillblad}

1. Frameworks tend to focus near-exclusively either on technical aspects of AI integration or on strategic and organisational considerations. This means there is a lack of models that holistically integrate technical, organisational, and innovation management perspectives.

2. Some frameworks re-formulate existing digital transformation models, but without addressing specific needs related to the development or implementation of AI.

3. Other frameworks focus exclusively on the ethical, legal, and social or technological robustness aspects or, alternatively, these aspects appear as one of separate dimensions, rather than integrated by design.

4. Several models have bolt-on rather than integrated AI as the end goal, sometimes framed as "enterprise cognitive computing", defined as improving business operations by automating repetitive tasks (Tarafdar et al., 2019). These frameworks concentrate on the more technical and operational dimensions, while frameworks looking at more integrated AI use cases focus more on strategy and organisation.

\section{Innovation Management and AI}

\section{Current research}

Current research lacks a systematic overview of how AI can support different elements of the innovation management system. While discussions occur on how to integrate AI into an organisation's products, features, and services, which can be both incremental or radically new, AI is also used to enable innovation during the process of developing new products and services (Cockburn et al., 2018). AI methods have been successfully applied for complexity and knowledge management in order to increase flexibility, and in more traditional applications, including process optimisation and automation, for increased efficiency and quality in product and service development (Raisch \& Krakowski, 2020). AI can strengthen innovation capability by increasing an organisation's ability to sense changes in the environment and predict what might happen next (Cockburn et al., 2018). An example would be predicting drug candidate selection by bringing together a vast array of previously disparate clinical and biophysical

\begin{tabular}{|c|c|}
\hline Model & Focus Areas \\
\hline Al Hierarchy of Needs - Monica Rogati (Rogati, 2017) & Data, tech \\
\hline Al Maturity Model (Alsheibani et al., 2019) & Technologies \& tools, data structure, people, organisation \\
\hline $\begin{array}{l}\text { The Al Maturity Playbook: Five Pillars of Enterprise Success } \\
\text { (Etlinger, 2018) }\end{array}$ & $\begin{array}{l}\text { Strategy, data science, product \& service development, } \\
\text { organisation \& culture, ethics \& governance }\end{array}$ \\
\hline Catalyst Fund - Al Readiness Toolkit (Catalyst Fund, 2018) & $\begin{array}{l}\text { Data, technologies,operations \& general management, } \\
\text { skills, ROI }\end{array}$ \\
\hline Element Al (Element Al, 2019) & $\begin{array}{l}\text { Strategy, technology \& data, people \& organisation, } \\
\text { governance }\end{array}$ \\
\hline $\begin{array}{l}\text { Ethics Guidelines for Trustworthy Al (European Commission, } \\
\text { 2019) }\end{array}$ & Ethics \\
\hline Kaleido Insights - Al Readiness (Groupman, 2018) & Strategy, people, data, infrastructure, ethics \\
\hline Microsoft - Landing AI Maturity Model (Microsoft, 2019) & Strategy, culture, organisation, capabilities \\
\hline MMC Ventures - The Al Playbook (MMC Ventures, 2019) & $\begin{array}{l}\text { Strategy, people, data, development, production, regulation } \\
\text { \& ethics }\end{array}$ \\
\hline Oracle Data Science Maturity Model (Oracle, 2018) & $\begin{array}{l}\text { Strategy, roles, collaboration, methodology, data awareness, } \\
\text { data access, scalability, asset management, tools, } \\
\text { deployment }\end{array}$ \\
\hline $\begin{array}{l}\text { Ovum (now Omdia) - How to Achieve Al Maturity and Why It } \\
\text { Matters (Pringle et al., 2018) }\end{array}$ & Strategy, organisation, data, technology, operations \\
\hline PwC Ethical Al Toolkit (PwC, 2019) & Ethics \\
\hline $\begin{array}{l}\text { The University of Chicago - Data Maturity Framework (UC, } \\
\text { 2018) }\end{array}$ & Data, tech, organisation \\
\hline
\end{tabular}

Figure 1. Overview of AI maturity models and frameworks 


\section{Integrated AI and Innovation Management: The Beginning of a Beautiful Friendship Nina Bozic Yams, Valerie Richardson, Galina Esther Shubina, Sandor Albrecht and Daniel Gillblad}

data, thereby fundamentally reshaping the function of idea generation in the innovation process of drug discovery (Ibid.).

Prem (2019) interviewed experts in Austria on the current use of AI in companies and suggests that while the range of applications is quite wide, the emphasis is currently on incremental improvements, with some examples of more radical innovation that would not be possible without AI, such as automation of sign language translation. Despite the potential for AI to radically innovate business models, current businesses are still focusing often on quality improvements rather than transforming business models.

Other challenges and barriers exist when it comes to integrating $\mathrm{AI}$ in organisations to strengthen their innovation capability. A lack of talent haunts IT fields in general, but even more so when it comes to AI experts (Loucks, 2018; Prem, 2019). Low AI competence and knowledge persists among managers, creating unrealistic expectations and disappointment around what is possible with AI, its costs, and how long it takes to develop innovative solutions (Prem, 2019). Credibility and trust in AI have also been widely questioned by management due to unexplainable learning systems, and lack of clarity around managers' responsibility for the smart and autonomous systems' behavior and possible legal implications that may arise from it (Ibid.)

\section{Innovation Management System Framework}

We use the "innovation management system" framework developed by the international standard ISO 56002 in this article to discuss how a more holistic integration of trustworthy AI could support different aspects of innovation management (see Figure 2).

Seven key components make up the ISO 56002 framework. The "Innovation Context of the Organisation" includes: a) scanning and analysing external environment, b) scanning and analysing internal environment, c) monitoring and understanding the needs of different stakeholders, d) promoting innovation culture, and e) developing collaboration internally and externally by building an innovation ecosystem.

The "Innovation Leadership" aspect involves: a) the development of innovation vision, strategy, and policy, b) defining innovation roles and responsibilities, and c)

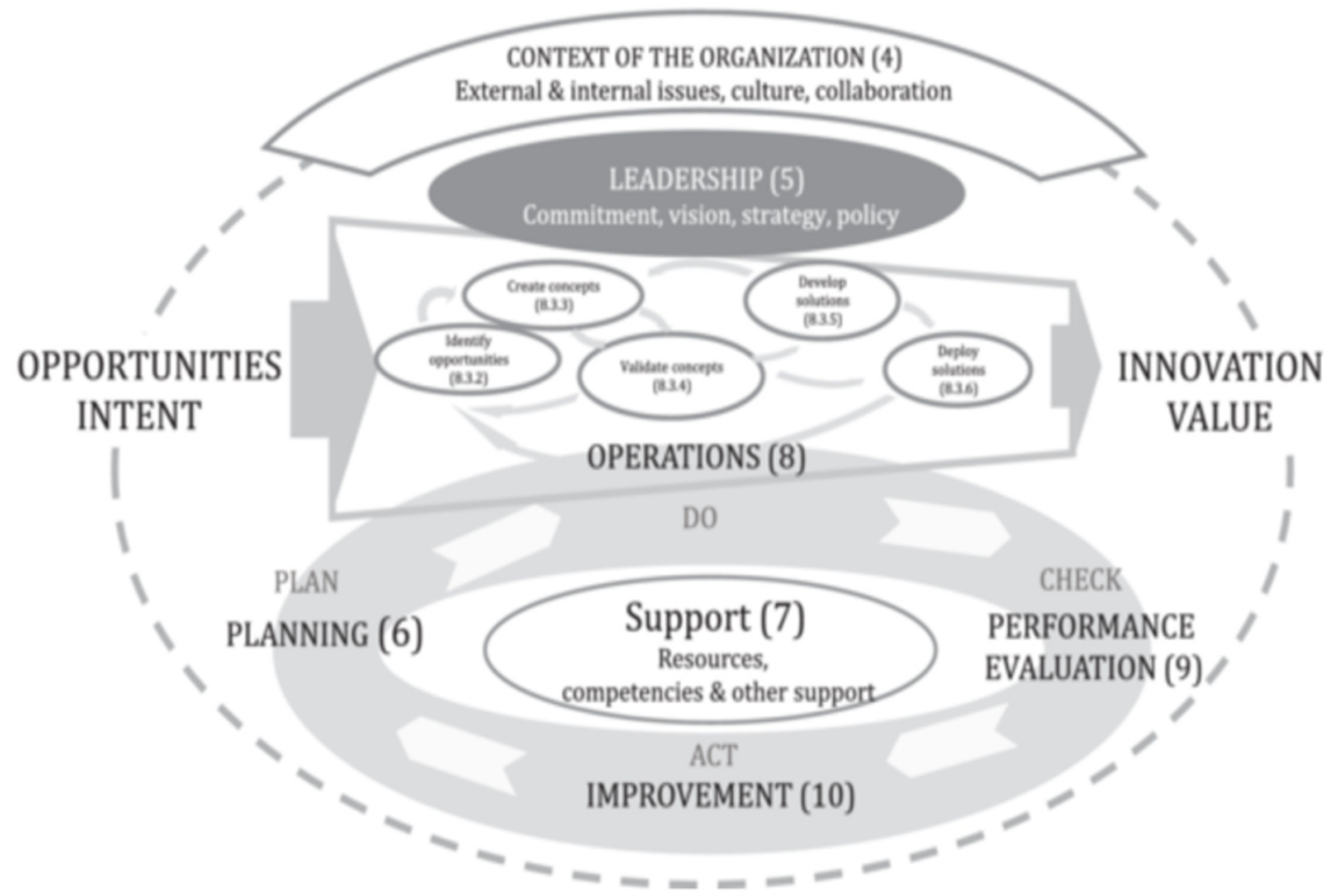

Figure 2. Innovation Management System, ISO 56002 


\section{Integrated AI and Innovation Management: The Beginning of a Beautiful Friendship Nina Bozic Yams, Valerie Richardson, Galina Esther Shubina, Sandor Albrecht and Daniel Gillblad}

the organisation supporting innovation. A company's innovation leadership thus needs to perform the "Planning" of innovation objectives, innovation portfolio and organisational structures that support innovation. "Innovation Operations" focuses on innovation initiatives and processes.

"Innovation Support" successfully guides the implementation of innovation management systems, including people, knowledge management, time, financial resources, physical and virtual innovation infrastructure, tools, methods, and competences. The last two parts of the innovation management system refer to "Performance Evaluation" and continuous "Improvement". Later in the Discussion section of this article, we suggest how AI could act as an enabler of various elements within the innovation management system presented here, with the support of the newly constructed AIMI.

\section{Methodology}

The development of our AIMI was influenced by the maturity model development framework proposed by de Bruin and Roseman (2005). Our approach consisted of three sequential and iterative research phases.

\section{Step 1: Define Scope - Analysis of existing models and literature}

To define the scope of our framework, we analysed existing models related to AI adoption and innovation. This was augmented with a literature review, including research papers and articles discussing AI integration. The background research included consideration of digital transformation maturity literature (Teichert, 2019), as well as design and development principles for maturity models (de Bruin and Roseman, 2005; Mettler 2009). While sparse academic research exists relating directly to AI maturity and its adoption path, we included Alsheibani and Messom's (2019) 'research-inprogress' maturity model in the review of existing frameworks. For the central notion of "trustworthy integrated AI", we chose the guidelines developed by the European Commission (2018).

Given how new this domain is, we found few academic research papers specifically about AI maturity models. A rare exception was a work-in-progress paper by Alsheibani and Messom (2019). This revealed a need to complement the current research with practitioner reports and best practices guides (Groupman, 2018; Ng, 2018; MMC Ventures, 2019; among others).
Finally, to broaden our insights into innovation management capabilities and the applicability of AI as it matures, we conducted a review of innovation frameworks (among others, Crossan and Apaydin, 2010; Bozic Yams, 2017; Tidd \& Bessant, 2018; ISO 56002, 2019) and innovation readiness assessments, including the Berkeley Innovation Index (Sidhu et al., 2016) and the KTH Innovation Readiness Level (2015).

Additionally, we reviewed work on sustainable innovation management and strategy as a good proxy for AI innovation, due to its general purpose qualities that require actions affecting whole organisations and ecosystems (McEwan and Schmidt, 2007; Laszlo et al., 2011).

\section{Step 2: Design - Iterative model design}

In this phase, the critical dimension of what represents maturity, rather than how maturity can be measured, was defined. This approach is recommended in newer domains where there is little evidence of what represents maturity (de Bruin and Roseman, 2005). Inspired by the work of Laszlo and Zhexembayeva (2011), we studied bolt-on AI and integrated AI notions, which were used to map maturity behaviours and the necessary capabilities to build a baseline of a mature AI business system (Mettler, 2009).

Given the complexity of the domain, any model must be able to tell a simplified, rather than merely simple story. Thus, a stage-gate approach is required to provide additional layers of detail, in the form of dimension components and subcomponents. This enables more granular maturity assessments for distinct areas (de Bruin and Roseman, 2005).

We reviewed the following multi-dimensional, staged innovation maturity frameworks: KTH Innovation Readiness Level (2015), Berkeley Innovation Index (Sidhu, 2016), and Capability Maturity Model Integrated, (CMMI Institute 2020). The prevalent, underlying entropy in many of the models did not suit a holistic approach to AI maturity. Instead, we developed a converging interwoven design with "trustworthy integrated AI" at the center. That is, the model introduced in the article proposes convergence, by design, towards robust, ethical, and legal AI that is embedded within virtually all dimensions of an organisation.

Step 3: Interviews with domain and subject matter experts We interviewed a cross-functional group of fourteen 


\section{Integrated AI and Innovation Management: The Beginning of a Beautiful Friendship Nina Bozic Yams, Valerie Richardson, Galina Esther Shubina, Sandor Albrecht and Daniel Gillblad}

experts one-on-one. The interviewees included innovation managers, senior public sector employees, AI researchers, data scientists, and AI leads within companies, as well as business leads, including one CEO and several CEO advisors. The interviews gave insights and understanding around how organisations are currently adapting AI, as well as how it is being augmented with their innovation management system. The authors also utilised their own broad industry experience in the AI, business strategy and innovation management sectors (among others, including Google, Ericsson, Spotify, GE and Northvolt).

\section{Results}

AIMI - AI Innovation Maturity Index
We developed an AI Innovation Maturity Index@ (AIMI) to provide a comprehensive framework, specifically designed to strive towards the goal of achieving trustworthy integrated AI. This framework combines the essential organisational, strategic, and technical conditions necessary for AI-based innovation, while also incorporating the central requirements for ethics, legality, and robustness.

\section{The Dimensions of AI Innovation Maturity}

The AIMI framework consists of six interconnected and interdependent dimensions, seen in Figure 3. A seventh dimension of "trustworthiness" was incorporated across the framework, interdependent with the six main dimensions. To create legal ethical systems that provide

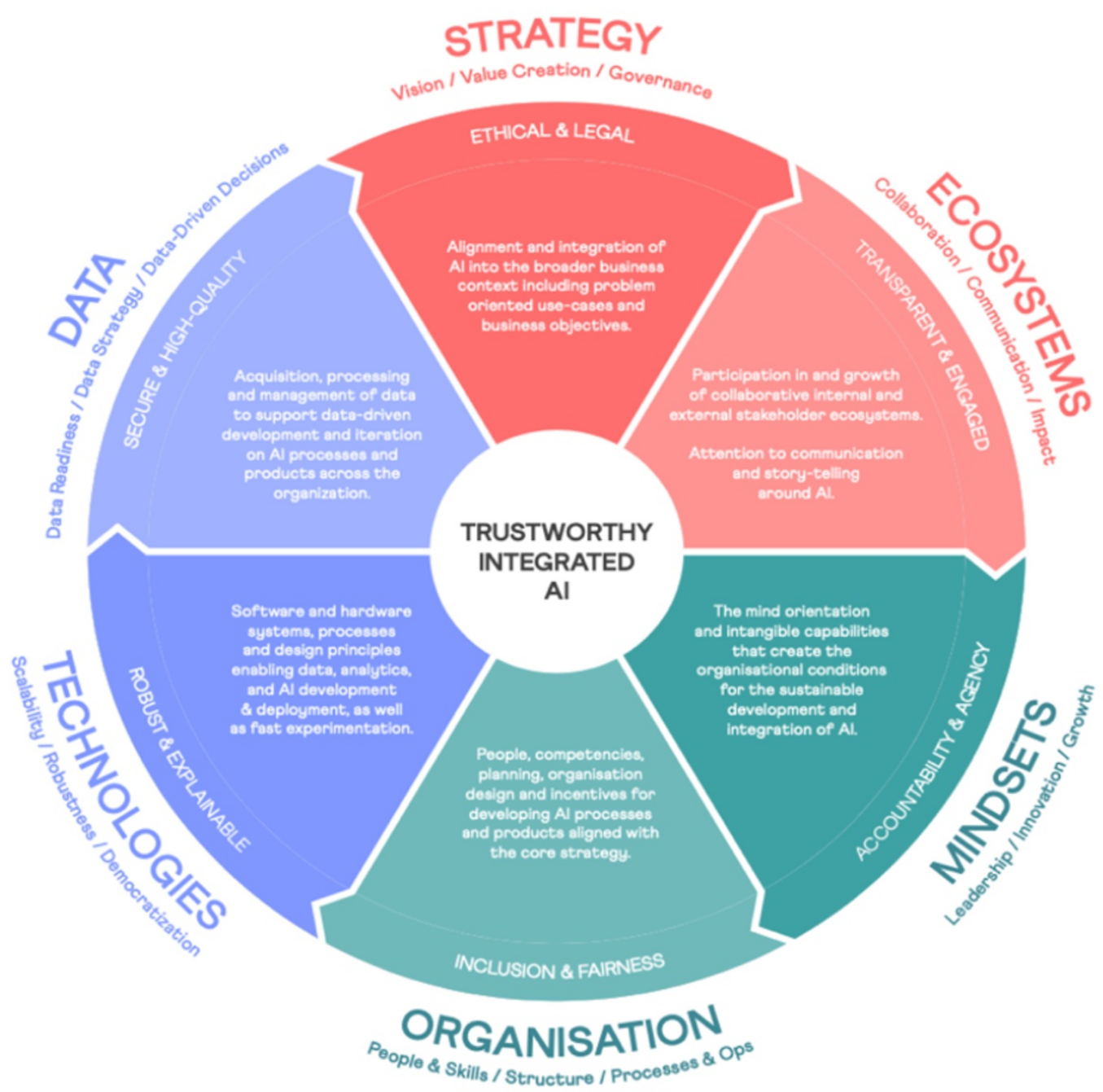

Copyright $(\subset) 2020$ Gradient Descent AB

Figure 3. AI Innovation Maturity Index (AIMI) 


\section{Integrated AI and Innovation Management: The Beginning of a Beautiful Friendship Nina Bozic Yams, Valerie Richardson, Galina Esther Shubina, Sandor Albrecht and Daniel Gillblad}

long-term durable value to citizens and that can be scaled successfully, this dimension needs integration "by design" (EC, 2019). To grow, organisations must develop maturity across all dimensions based on "design principles". The seven dimensions shown are not mutually exclusive and should be viewed as enabling each other.

The Strategy dimension is concerned with the vision, value creation, and governance of an organisation. Specifically, it addresses the ability to align and integrate AI into the broader business context, by defining problem-oriented use-cases and business objectives. In short, it provides the "why" for "what" AI activities organisations undertake.

The Ecosystems dimension is about the level of collaboration, communication, and impact that an organisation achieves with its internal and external stakeholders, partners, and collaborators. As a complex subject, organisations need to develop a common understanding, vocabulary, and storytelling around AI both internally and externally. Communication quality helps as an important indicator of maturity. Successfully integrating AI requires cooperation across the organisation from strategy to data collection and technology, with similar cooperation needed externally.

The Ecosystems dimension is strongly linked to Strategy. Notwithstanding AI, digital maturity often drives dramatic changes in organisations' business ecosystems, making them larger, more complex, and even more critical to business strategy. Ecosystems enable organisations to respond to, and exist in, an increasingly digital environment. Organisations must make conscious strategic decisions about what role they intend to have in the wider ecosystem, whether it be as an observer, a participant, or an orchestrator, which in itself defines maturity in this dimension.

The Mindsets dimension is concerned with the behaviour, culture, and systems within organisations. The mindset orientation of leadership, and their nurturing of an innovation and growth mindset will determine the degree to which an organisation can succeed in its AI endeavours. The AIMI framework defines Mindsets as the mental orientation and intangible capabilities that create the organisational conditions for sustainable development through integration of AI.

The Organisation dimension includes the people, skills, structures, processes, and operations aspects. It is effectively about how a business can organise itself for integrating AI. The Organisation plays an important role in hiring, training, educating, and upskilling employees' AI skills. The organisational elements are also critical to fostering a mindset of growth, cross-functional collaboration, and more distributed decision making. From a process and operations point of view, this dimension also covers the tools that reduce friction in internal and external collaboration. The Organisation can partly be considered a tangible representation of the Mindsets.

The Data dimension is central for AI, as data represents the underlying fuel for most AI algorithms. It is also essential for evaluating the performance of machine learning algorithms, thereby enabling companies to make data-informed decisions. Data can also be a source of competitive advantage via the self-reinforcing virtuous circle of data $(\mathrm{Ng}, 2018)$, and sustainable data dominance, with data-enabled learning network effects (Hagiu and Wright, 2020). Briefly, this dimension is concerned with data preparedness, data strategy, and data-driven decisions made inside an organisation.

The last dimension is Technology, often called "data infrastructure" among technical practitioners. It represents a company's software and hardware systems, processes and design principles enabling data, analytics, and thus, potential for AI development and deployment. Technology for AI needs to be scalable, support multiple diverse use cases, and enable fast iteration. Good technology selection and data sets allow for internal data democratisation - the ability for less technical users to themselves create insights from data. The Data and Technology dimensions together represent a company's ability to physically create and operationalise AI applications.

\section{Stages of AI Maturity}

The progression to trustworthy integrated AI typically has five stages, from foundational to integrated. It represents growth in AI competency and of the organisational mindset towards a more integrated, systems-of-systems, transformative innovation approach. This mindset of growth is important for an organisation's long-term; not just for AI-enabling innovation, but also for a company's sustainability and other complex technological innovations. The process of AI maturation and organisational mindset growth enable each other. 


\section{Integrated AI and Innovation Management: The Beginning of a Beautiful Friendship Nina Bozic Yams, Valerie Richardson, Galina Esther Shubina, Sandor Albrecht and Daniel Gillblad}

\begin{tabular}{|c|c|c|c|c|}
\hline Foundational & Experimenting & Operational & Inquiring & Integrated \\
\hline $\begin{array}{l}\text { General curiosity about Al, limited } \\
\text { understanding of it and its } \\
\text { applicability to the business / industry. }\end{array}$ & $\begin{array}{l}\text { Less hype around Al. Beginnings of } \\
\text { a mindset change in the } \\
\text { organization. Developing an } \\
\text { understanding of the iterative / } \\
\text { experimental process needed for } \\
\text { developing Al. }\end{array}$ & $\begin{array}{l}\text { Strategic and organisational } \\
\text { alignment, including } \\
\text { governance, occurs to scale } \\
\text { proven } \mathrm{Al} \text { use cases. }\end{array}$ & $\begin{array}{l}\text { The business understands the } \\
\text { transformational power of } \mathrm{Al} \\
\text { for the organization / market / } \\
\text { industry and develops the } \\
\text { necessary strategic } \\
\text { orientation and mindset } \\
\text { capacities. }\end{array}$ & $\begin{array}{l}\text { Trustworthy Integrated } \mathrm{Al} \text { is at } \\
\text { the core of the business } \\
\text { strategy with the capacity to } \\
\text { develop new applications and } \\
\text { business models and affect the } \\
\text { markets and ecosystems. }\end{array}$ \\
\hline $\begin{array}{l}\text { Some grassroots efforts or small- } \\
\text { scale, opportunistic use-cases are } \\
\text { likely driven by self-motivated } \\
\text { individuals and tend to focus on short- } \\
\text { term ROI (efficiency gains, risk } \\
\text { reduction), often linked to internal } \\
\text { processes rather than the core } \\
\text { organization domain. }\end{array}$ & $\begin{array}{l}\text { Move from limited understanding } \\
\text { and competence to building their } \\
\text { first relevant } \mathrm{Al} \text { applications, small } \\
\text { data science/Al teams and initial } \\
\text { data infrastructure. }\end{array}$ & $\begin{array}{l}\text { Investments increase and a } \\
\text { solid data infrastructure is in } \\
\text { place with a small central } \\
\text { team working with } \mathrm{Al} \text { and } \\
\text { analytics/decision support. }\end{array}$ & $\begin{array}{l}\text { Innovation-based product and } \\
\text { business strategy exploration } \\
\text { gains momentum. The } \\
\text { organization becomes more } \\
\text { external and future-facing with } \\
\text { regards to the ecosystem and } \\
\text { R\&D }\end{array}$ & $\begin{array}{l}\text { The organization reaches a } \\
\text { self-transforming stage - able to } \\
\text { learn, evaluate, adjust, invest in } \\
\text { the future. It can experiment } \\
\text { and explore at multiple levels } \\
\text { from strategy to technology. }\end{array}$ \\
\hline $\begin{array}{l}\text { Little to no data and data } \\
\text { infrastructure nor data-driven } \\
\text { experimentation culture. }\end{array}$ & $\begin{array}{l}\text { May not have a clear Al strategy } \\
\text { and experiments are not directly } \\
\text { linked to top-line business strategy. } \\
\text { More deliberate planning is } \\
\text { underway but the organisation is } \\
\text { still siloed with differing goals, } \\
\text { resources and vision. }\end{array}$ & $\begin{array}{l}\text { Speed of iterative } \\
\text { experimentation increases, } \\
\text { backed by knowledge, data } \\
\text { and technology. Virtuous } \\
\text { cycle of data is activated. } \\
\text { There is a transactional } \\
\text { approach with the wider } \\
\text { ecosystem, where needed, to } \\
\text { operationalise current use } \\
\text { cases and identify possible } \\
\text { new means of value creation. }\end{array}$ & $\begin{array}{l}\text { Organization develops its own } \\
\text { external ecosystem with } \\
\text { academic partners, other } \\
\text { companies, diverse types of } \\
\text { specific as well as open- } \\
\text { ended collaborations. }\end{array}$ & $\begin{array}{l}\text { Significant and continuous R\&D } \\
\text { investment enables } \\
\text { experimentation, risk-taking } \\
\text { and feasibility evaluations, now } \\
\text { with clearer systematic } \\
\text { understanding of how it shapes } \\
\text { future value-creation. }\end{array}$ \\
\hline
\end{tabular}

Figure 4. AI Innovation Maturity Index (AIMI)

The five stages of maturity are Foundational, Experimenting, Operational, Inquiring, and Integrated. A summary of the stages is provided in Figure 4.

\section{Stages of Maturity Descriptions}

It is beyond the scope of this article to discuss all the patterns and anti-patterns of each stage. We present only their main features in Figure 4 and a brief characterisation below.

Foundational Stage: This stage is characterised by a limited understanding of AI. A nascent curiosity may surround it, but with no clear grasp of the relevant and useful cases and applications. Some opportunistic bolton AI use cases may have started with a focus on return on investment. In more digital organisations, some grassroots efforts from the technical employees have taken place to get simple AI projects going. But, generally, no real AI specific budget or process exists at this point.

Experimenting Stage: At this stage, an organisation builds capabilities to execute on more straight-forward AI applications. These include technical capabilities, people capabilities (including hiring and learning), and developing a more experimental mindset. A key feature of this stage is discovering, cleaning, and making usable any data the organisation has, as well as instrumenting existing systems to get more quality data. This is an "action" stage, with a focus on a few specific projects based on identified internal needs.

Operational Stage: Here, organisations have a few scaled AI use cases, and the technical and organisational capacity to keep them going. They can start reaping the benefits of built-up knowledge and capacity around AI to create new applications with higher speed. They have good internal analytics and quality data that can be applied to multiple use cases. At this point, organisations tend to move from a business optimisation approach to an outward and forwardlooking innovation strategy and mindset. Awareness of the importance of the external ecosystem and engagement with it becomes increasingly common.

Inquiring Stage: At this point, major shifts in the leadership mindset and strategic orientation take place. The organisation understands that $\mathrm{AI}$ is not just a technology, but the basis for bigger organisation/market/industry transformations. Innovation-based product and business strategy exploration occurs and gains momentum, backed by 


\section{Integrated AI and Innovation Management: The Beginning of a Beautiful Friendship Nina Bozic Yams, Valerie Richardson, Galina Esther Shubina, Sandor Albrecht and Daniel Gillblad}

capabilities developed in the previous stages. The organisation becomes more external- and future-facing with regards to the ecosystem and R\&D. Structurally, the business may be moving towards self-organised, flexible teams, driven by a common sense of purpose.

Integrated Stage: Very few organisations today have reached this stage. Examples would include companies such as Google, Amazon, and Baidu, whose competitive advantage derives from $\mathrm{AI}$ and the associated "virtuous circle of data", that reinforces their existing business, and creates possibilities for further business innovation and transformation. Furthermore, the enabling structures, processes, technologies, and operations are in place to accelerate their AI agility, supported by an understood sense of purpose and strategic alignment centred on value creation and purpose.

While theoretically possible, existing companies (not AI startups) tend to have difficulties moving toward integrated AI (Fountaine et al., 2019) and more complex data-driven business behaviours. This usually first requires building up both technical and organisational capabilities and knowledge with bolt-on AI applications. While there is some fluidity, our findings from interviews and workshops with companies in Sweden show that most companies today are in the early phase of AI development, using a bolt-on AI approach.

\section{Discussion}

\section{AIMI \& Innovation Management System}

AIMI and innovation management system (IMS, ISO 56002) models include many shared elements, from strategy, leadership, culture, processes, organisation, ecosystem, and more. To fully exploit the potential of AI and to reach higher inquiries and integrated levels of maturity, general conditions for innovation in organisations need to be met. At the same time, integrating trustworthy AI into organisations can support various aspects of the innovation management system and increase the overall innovation capability of an organisation. Strategic implementation of AI and innovation management in organisations thus go handin-hand and can mutually complement and enable each other.

In Figure 5, we mapped several elements of the innovation management system according to ISO 56002, and give examples of how AI technologies could be used to support and augment those elements to increase organisational innovation capability. In general, four recurring topics can be observed.

1. First, AI technologies can be applied to democratise and distribute innovation across organisations, instead of centralising it within a specific function or department. This can be done by using AI to automate routine tasks, thereby freeing up employee time for more innovation, and repurposing their work towards innovation as a core activity. By building a data-driven organisation, employees can use AI-supported systems for more informed decision-making. To reach their greater potential of democratising innovation with the help of AI, organisations need to reach higher levels of AI maturity, such as are found at the Inquiring and Integrated stages. While the automation of work tasks and business processes, along with data-driven decision-making are starting to happen at earlier stages already, it is usually either optimisation (and not innovation) driven, or limited to a specific part of an organisation.

2. Second, integrating trustworthy AI into organisations can increase diversity, cross-functional and interdisciplinary collaboration. This is achieved by enabling more diverse talent recruitment and team formation with respect to human resources. AI technologies can be applied to break down organisational silos, by building recommendation systems that match individuals and teams with interesting potential collaborators from within an organisation and outside of it, depending on the challenge they are addressing. AI systems can even be used to assess the innovation potential of external partners from a wider innovation ecosystem, as a way to optimise investments in external collaborations. Here again, bolt-on AI approaches might be used for specific functions (such as HR recruitment) in early maturity stages. Nevertheless, the full potential of AI will only be reached at the higher Inquiring and Integrated maturity stages as innovative culture and flexible organisational structures more fully merge with AI across an organisation.

3. Third, AI technologies can be applied to increase organisational capacity for sensing future potentialities. Organisations can move from a reactive to more proactive mode based on AI-supported predictions that help organisations become aware of signals of change in stakeholder behavior and macro trends, thus enabling them to better identify possible future needs. Consequently, organisations can become better at embracing risk-taking and uncertainty, reaching higher 


\section{Integrated AI and Innovation Management: The Beginning of a Beautiful Friendship Nina Bozic Yams, Valerie Richardson, Galina Esther Shubina, Sandor Albrecht and Daniel Gillblad}

\begin{tabular}{|c|c|c|c|c|}
\hline Innovation context & Innovation leadership & $\begin{array}{l}\text { Innovation } \\
\text { operations }\end{array}$ & Innovation support & $\begin{array}{l}\text { Innovation } \\
\text { performance }\end{array}$ \\
\hline $\begin{array}{l}\text { Scan external } \\
\text { environment } \\
\text { Al can be used to scan } \\
\text { large amount of macro } \\
\text { data \& trends, industry } \\
\text { \& competitors' data, } \\
\text { identifying pain points, } \\
\text { in-time recognition of } \\
\text { customer/stakeholder } \\
\text { needs and prediction of } \\
\text { future needs } \\
\text { Scan internal } \\
\text { environment } \\
\text { Al can be used to scan } \\
\text { internal data and } \\
\text { processes, supporting } \\
\text { alignment with org } \\
\text { values (e.g. to increase } \\
\text { inclusion, participation } \\
\text { \& diversity) } \\
\text { Innovation culture } \\
\text { Al can be used to } \\
\text { understand culture/ } \\
\text { identify patterns in } \\
\text { human behavior that } \\
\text { would not be seen } \\
\text { through common } \\
\text { questionnaires (for } \\
\text { example, pattern } \\
\text { identification in } \\
\text { analyzing internal } \\
\text { communication) } \\
\text { Innovation ecosystem } \\
\text { Al can be used to } \\
\text { support matchmaking } \\
\text { with the right innovation } \\
\text { partners, assessing their } \\
\text { innovation capability }\end{array}$ & 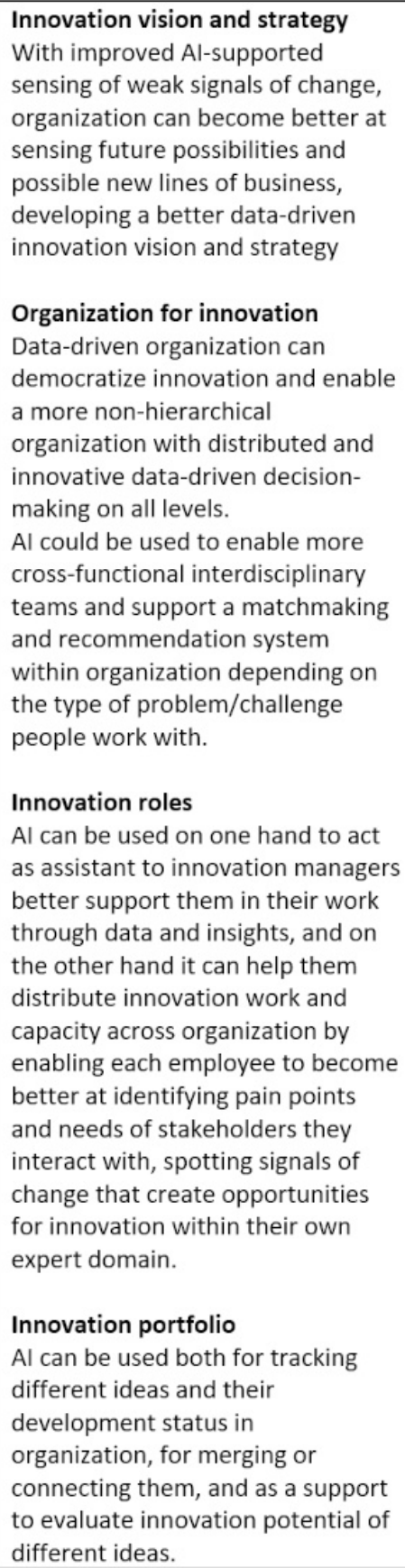 & $\begin{array}{l}\text { Identifying } \\
\text { opportunities } \\
\text { Data-driven product } \\
\text { and service } \\
\text { development through } \\
\text { identification of pain- } \\
\text { points, needs and } \\
\text { opportunities with } \\
\text { complex Al analytics. } \\
\text { Concept creation \& } \\
\text { validation } \\
\text { Al can be used to go } \\
\text { beyond tunnel vision } \\
\text { in innovation process, } \\
\text { identifying } \\
\text { unexpected } \\
\text { correlations between } \\
\text { different concept } \\
\text { ideas and broadening } \\
\text { concepts by } \\
\text { connecting them to } \\
\text { other fields. } \\
\text { Solutions } \\
\text { development } \\
\text { Al can be used for } \\
\text { verification and } \\
\text { testing of solutions, } \\
\text { analyzing trouble } \\
\text { reports, and } \\
\text { proactively predicting } \\
\text { possible } \\
\text { failures/defects } \\
\text { Solutions deployment } \\
\text { Through virtuous cycle } \\
\text { of data, you can } \\
\text { enable continuous } \\
\text { improvement of } \\
\text { products and services } \\
\text { with iterative loops of } \\
\text { feedback data and fast } \\
\text { improvements }\end{array}$ & $\begin{array}{l}\text { Attracting \& retaining talent } \\
\text { Al supported talent } \\
\text { recruitment tools can be } \\
\text { used to increase diversity } \\
\text { and create a better fit, which } \\
\text { increases also retention } \\
\text { Knowledge management } \\
\text { Al can be used for } \\
\text { automating and optimize } \\
\text { KM, e.g. automated note } \\
\text { taking in meetings and } \\
\text { making personalized } \\
\text { knowledge sharing } \\
\text { recommendations } \\
\text { Time \& budget for } \\
\text { innovation } \\
\text { Al can release extra time and } \\
\text { financial resources for } \\
\text { innovation work by } \\
\text { automating more routine } \\
\text { tasks and freeing up more } \\
\text { resources for innovation } \\
\text { which can thus become a } \\
\text { core task of everyone in } \\
\text { organization } \\
\text { Physical \& virtual } \\
\text { infrastructure/ Innovation } \\
\text { methods \& tools } \\
\text { Al supported innovation } \\
\text { tools which can augment } \\
\text { human creativity with } \\
\text { insights from analyzing } \\
\text { complex and diverse sets of } \\
\text { data } \\
\text { Innovation competence } \\
\text { development } \\
\text { Al can be used to enable } \\
\text { personalized learning } \\
\text { (adjusting timing and } \\
\text { training methods to specific } \\
\text { needs of employees) }\end{array}$ & $\begin{array}{l}\text { Measure/evaluate } \\
\text { performance } \\
\text { Al can be used to } \\
\text { track complex sets } \\
\text { of innovation } \\
\text { performance } \\
\text { related data, not } \\
\text { only analyzing } \\
\text { what's happening } \\
\text { today but predicting } \\
\text { what might happen } \\
\text { tomorrow to better } \\
\text { manage potential } \\
\text { risks and embrace } \\
\text { uncertainties, } \\
\text { increasing potential } \\
\text { for radical } \\
\text { innovation } \\
\text { Plan and act for } \\
\text { improvement } \\
\text { With the help of } \\
\text { predictive analytics, } \\
\text { a more proactive } \\
\text { (instead of reactive) } \\
\text { approach to } \\
\text { continuous } \\
\text { development of } \\
\text { innovation system is } \\
\text { enabled, helping } \\
\text { organization not } \\
\text { only incrementally } \\
\text { improve its IMs, but } \\
\text { potentially disrupt it }\end{array}$ \\
\hline
\end{tabular}

Figure 5. Mapping AI support to different aspects of the Innovation Management System 


\section{Integrated AI and Innovation Management: The Beginning of a Beautiful Friendship Nina Bozic Yams, Valerie Richardson, Galina Esther Shubina, Sandor Albrecht and Daniel Gillblad}

levels of ambidexterity, complementing incremental innovation with more radical innovation. At earlier stages of AI integration, bolt-on solutions can be used for specific functions, like predictive AI analytics in business intelligence or marketing, while the ability to realise the future potential of AI will be distributed across organisation only at the later Inquiring and Integrated stages.

4. Lastly, AI technologies can support the development of a learning organisation, where learning is personalised and adjusted to the needs, preferences, and learning styles of each employee. Some aspects of knowledge management (like taking notes at meetings and systematising knowledge documentation) can be automated with personal recommendation systems used to only share knowledge that is relevant and interesting for individual employees. This stimulates creativity and continuous desire for learning. When adopting AI, bolton applications might first be tested to automate certain parts of a company's knowledge management and to introduce personalised learning for some employee development programs. A more broadly developed learning organisation enabled by AI will only happen at later stages where $\mathrm{AI}$ is embedded and interlinked with innovation, together with adopting a data-driven learning mindset and culture across the organisation.

Despite the potential future impact of trustworthy integrated AI on various aspects of innovation management systems, most organisations are currently in either the Foundational or Experimenting maturity stages of AI integration, running ad hoc pilot projects or applying AI in a single business process (Fountaine et al., 2019). We believe that organisations need to move towards the Inquiring and Integrated stages in order to start increasing not only incremental innovation, but also to strengthen organisational capacity for more radical innovation with $\mathrm{AI}$ as the enabler. The result could be AI-driven innovation, that supports new ways of adaptive organising based on distributed decisionmaking, and innovative business models that introduce completely new lines of business.

We find it interesting to address the question of how the role of innovation management might change in organisations as they reach higher levels of trustworthy AI integration. We see glimpses of this in some AI-driven start-ups today, run by a new generation of progressive leaders that fully embrace the possibilities of humanmachine augmentation and self-organisation, where innovation management as an organisational function is not needed anymore, because continuous innovation has become both a core skill and business for everyone in the organisation. Some of these AI-driven start-ups have the potential to become true disruptors and successfully challenge established incumbent businesses by appealing to lower-end, unserved, or underserved consumers, and then migrating to a mainstream market (Christensen et al., 2015). Since incumbents often focus on improving their products and services for their most demanding and profitable customers, they tend to ignore the needs of others (Ibid.). AI systems can enable disruptors to identify the unserved or underserved customers, test their proposals and market offers quickly, and through instant feedback loops, respond intime to customer needs. On the other hand, incumbents could use AI-driven foresight to detect potential disruptors earlier. They could use data-driven foresight techniques to detect new market niches and start developing new product cycles more quickly than is possible today. AI technologies could consequently prevent a company from overlooking unserved or underserved market segments, and help them respond faster to new emerging customer needs.

\section{Conclusion}

This article has aimed to build on previous literature and develop a more comprehensive view of the complex relationship between integrated AI and innovation management. It raised important questions around how integrated AI may affect the role of innovation management in the future and how it can increase an organisation's innovation capability. It demonstrated the need for two different experimentation stages: first, an initial AI adoption level that strengthens an organisation's capacity for optimisation and incremental innovation (from Foundational to Operational stages); and following that, one where organisations reach Inquiring and Integrated AI maturity levels that drive more radical or disruptive innovation. As this is still an emerging area, the article introduced what we call an AI Innovation Maturity Index (AIMI) framework. This framework can be used to systematically support the integration of $\mathrm{AI}$ into innovation management systems and is designed to increase an organisation's capability for radical innovation.

We intend AIMI to be used as a compass, map, and tool. It enables joint sense-making around best practices needed to holistically integrate AI into organisations, thereby enabling and accelerating innovation. For business and public sector organisations, the framework 


\section{Integrated AI and Innovation Management: The Beginning of a Beautiful Friendship Nina Bozic Yams, Valerie Richardson, Galina Esther Shubina, Sandor Albrecht and Daniel Gillblad}

shows which aspects they need to develop (often in parallel), what the journey might look like for them, how well they are doing so far, and what types of help they should engage at different stages of maturity to derive the most value. For innovation management researchers and practitioners, AIMI offers suggestions on how AI can be used in various ways as an innovation enabler, helping to move organisations from incremental towards more radical innovation.

The AIMI model needs to be tested more widely in practice to fully demonstrate its value and application opportunities. For this, an assessment tool could be developed to support the model and enable systematic evaluation of a company's current AI maturity status, thus assisting with strategic planning for $\mathrm{AI}$ integration.

We believe that integrating trustworthy integrated AI into organisations can serve to support various aspects of the innovation management system (ISO 56002, 2019) as well as increasing the overall innovation capability of an organisation. AI technologies can be applied to democratise and distribute innovation across organisations, to increase diversity, cross-functional and interdisciplinary collaboration, to strengthen organisational capacity for sensing future potentialities, and to support the development of a true learning organisation. Strategic implementation of $\mathrm{AI}$ and innovation management in organisations go hand-inhand. Thus, we believe that further exploration of their integration could mark the beginning of a beautiful friendship.

\section{References}

Alsheibani, S. and Messom, C. 2019. Towards an Artificial Intelligence Maturity Model: From Science Fiction to Business Facts. Paper presented at the Twenty-Third Pacific Asia Conference on Information Systems, China. Available at:

http://www.pacis2019.org/wd/Submissions/PACIS20 19_paper_146.pdf.

Bozic Yams, N. 2017. Integrated Model of Innovative Competence. Journal of Creativity and Business Innovation, 3: 140-169.

Cam, A., Chui, M., and Hall, B. 2019. Global AI Survey: AI proves its worth, but few scale impact. McKinsey
Company. Available at:

https://www.mckinsey.com/featured-

insights/artificial-intelligence/global-ai-survey-ai-

proves-its-worth-but-few-scale-impact, accessed March 2020.

CMMI Institute. 2020. Capability Maturity Model Integration. Available at:

https://cmmiinstitute.com/learning/appraisals/level s, accessed March 2020.

Catalyst Fund. 2018. AI Readiness Toolkit. Tech Startups 101 website. Available at: https: //www.techstartups101.com/ai-readiness-toolkit, accessed June 2019.

Christensen, C.M., Raynor, M. and McDonald, R. 2015. What is disruptive innovation? Harvard Business Review, December Issue.

Cockburn, I., Henderson, R. and Stern, S. 2017. The Impact of Artificial Intelligence on Innovation. National Bureau of Economic Research, Working Paper No. 24449, JEL No. L1.

Available at: http://www.nber.org/papers/w24449.

Crossan, M. M. and Apaydin, M. 2010. A MultiDimensional framework of Organizational Innovation: A Systematic Review of the literature. Journal of Management Studies, 47(6): 1154-1191.

de Bruin, T., and Roseman, M. 2005. Understanding the main phases of developing a maturity assessment model. Proceedings of the 16th Australasian Conference on Information Systems, Australia 2005.

Element AI. 2019. AI from exploring to transforming: Introducing the AI Maturity Framework. Available at: https://www.elementai.com/news/2019/exploringto-transforming-introducing-the-ai-maturityframework, accessed June 2019.

Etlinger, S. 2018. The AI Maturity Playbook: Five Pillars of Enterprise Success. Altimeter@Prophet Research Report, December.

European Commission (EC), High Level Expert Group on Artificial Intelligence. 2019. Ethics Guidelines for Trustworthy AI. Made public April 8, 2019. Available at:

https://ec.europa.eu/futurium/en/ai-allianceconsultation.

Fleming, N. 2018. How Artificial Intelligence is Changing Drug Discovery. Nature, 557: S55-S57.

Fountaine, T., McCharty, B. and Saleh, T. 2019. Building the AI-Powered Organization. Harvard Business Review, July-August issue: 63-73.

Groupman, J. 2018. AI Readiness: Five Areas Businesses Must Prepare for Success in Artificial Intelligence. Kaleido Insights Research report.

Hagiu, A. and Wright, J. 2020. When Data Creates Competitive Advantage. Harvard Business Review, January-February Issue. Available at https://hbr.org/2020/01/when-data-createscompetitive-advantage, accessed April 2020. 


\section{Integrated AI and Innovation Management: The Beginning of a Beautiful Friendship Nina Bozic Yams, Valerie Richardson, Galina Esther Shubina, Sandor Albrecht and Daniel Gillblad}

International Organisation for Standardization (ISO) 56002. 2019. Innovation management - Innovation management system - Guidance.

KTH 2015. Innovation Readiness Level. Stockholm: KTH. Available at: https://kthinnovationreadinesslevel.com, accessed in 2019.

Laszlo, C. and Zhexembayeva, N. 2011. Embedded Sustainability: The Next Big Competitive Advantage. Greenleaf Publishing.

Loucks J., Davenport T., Schatsky D. 2018. State of AI in the Enterprise. Deloitte Insights Report.

Mettler, T. 2011. Maturity Assessment Models: A Design Science Research Approach. International Journal of Society Systems Science, 1/2(1/2): 81-98.

Microsoft. 2019. AI Readiness Assessment Tool. Available at:

https://info.microsoft.com/ww-landing-ai-maturitymodel-website.html, accessed September 2019.

MMC Ventures. 2019. The AI Playbook: The step-by-step guide to taking advantage of AI in your business. Available at:

https://www.ai-playbook.com, accessed November 2019.

McEwan, C. and Schmidt, J. 2007. Mindsets in Action: Leadership and the Corporate Sustainability Challenge. Avastone Consulting Report.

Nagji, B. and Tuff, G. 2012. Managing Your Innovation Portfolio. Harvard Business Review. Available at: https://hbr.org/2012/05/managing-your-innovationportfolio

Ng, A. 2018. AI Transformation Playbook: How to lead your company into the AI era. Available at https://landing.ai/ai-transformation-playbook, accessed July 2019.

Oracle. 2018. A Data Science Maturity Model for Enterprise Assessment. Available at https://blogs.oracle.com/r/a-data-science-maturitymodel-for-enterprise-assessment-part-1, accessed September 2019.

Paulk M.C. 2009. A History of the Capability Model for Software. ASQ Software Quality Professional. Volume 12 , Issue 1.

Prem, E. 2019. Artificial Intelligence for Innovation in Austria. Technology Innovation Management Review. Volume 9, Issue 12: 5-15.

Pringle, T. and Zoller, E. 2018. How to Achieve AI Maturity and Why it Matters. Ovum TMT Intelligence Report.

PricewaterhouseCoopers (PwC). 2019. PwC Responsible AI Diagnostic. Available at:

https://www.pwc.com/gx/en/issues/data-andanalytics/artificial-intelligence/what-is-responsibleai.html, accessed September 2019.
Raisch, S. and Krakowski, S. 2020. Artificial Intelligence and Management: The Automation-Augmentation Paradox. Academy of Management Review. https://doi.org/10.5465/2018.0072, accessed March 2020.

Rogati, M. 2017. The AI Hierarchy of Needs. Hacker Noon. Available at:

https:/ / hackernoon.com/the-ai-hierarchy-of-needs18f111fcc007, accessed 2017.

Sidhu, I., Goubet, J-E., and Pries, C. 2016. Berkeley Innovation Index: An Approach for Measuring and Diagnosing Individuals' and Organizations' Innovation Capabilities. Sutardja Center for Entrepreneurship \& Technology at University of California, Berkeley.

Teichert, R. 2019. Digital Transformation Maturity: A Systematic Overview of Literature. Acta Universitatis Agriculturae et Silviculturae Mendelianae Brunensis, 67(6): 1673-1687.

Tarafdar M., Beath C.M., and Ross J. 2019. Using AI to Enhance Business Operations. MIT Sloan Management Review, Summer.

Tidd, J. and Bessant, J.R. 2018. Managing Innovation: Integrating Technological, Market and Organizational Change. Wiley.

The University of Chicago (UC). 2018. Data Maturity Framework. Center for Data Science and Public Policy.

Zuboff, Shoshana 2019. The Age of Surveillance Capitalism: The Fight for a Human Future at the New Frontier of Power. New York: Public Affairs.

\footnotetext{
Citation: Yams, N.B., Richardson, V., Shubina, G.E., Albrecht, S Gillblad, D. 2020. Integrated AI and Innovation Management: The Beginning of a Beautiful Friendship. Technology Innovation Management Review, 10(11): 5-18.

http://doi.org/10.22215/timreview/1399

Keywords: Artificial intelligence, innovation management, maturity model, AI innovation, AI maturity, IMS ISO 56002
} 


\section{Integrated AI and Innovation Management: The Beginning of a Beautiful Friendship Nina Bozic Yams, Valerie Richardson, Galina Esther Shubina, Sandor Albrecht and Daniel Gillblad}

\section{About the Authors}

Nina Bozic, PhD, Senior Researcher in Innovation Management and the Future of Work, RISE Research Institutes of Sweden Nina has a PhD in Innovation Management and 16 years of experience working as an innovation enabler and explorer, both in companies and public sector organizations. After starting her career as a management consultant at Deloitte and building an entrepreneurship centre CEED Slovenia, she moved to Sweden where she continued her work as an innovation consultant and participatory action researcher, working with organizations, such as Nacka, Eskilstuna and Västerås municipalities, ABB, Electrolux, Ericsson, GodEl and others. In the last two years she has been researching the future of work, and how we can integrate innovation management with other disciplines, such as AI, new models of organizing, and future studies to prepare organizations for the future in a more holistic way.

Valerie Richardson, AI Strategist \& Partner at Gradient Descent. Valerie is an experienced leader and advisor in digital disruption and transformation with over 20 years at Google and General Electric, helping companies in multiple industries solve strategic and operational problems in an integrated way across multiple technology domains. Her expertise includes defining digital strategies and developing digital operating models with a focus on providing practical solutions to complex technology challenges for executives. She has a specific interest in emergent technologies, including $\mathrm{AI}$ and IoT. Valerie most recently led a digital division of General Electric, advising large industrial operations on how to implement cloudbased enterprise IoT software, data analytics, machine learning and AI to increase productivity, reduce costs and improve competitiveness.

Galina Esther Shubina, AI Technologist \& Partner at Gradient Descent. Galina spent 16 years in the tech industry, over a decade of it at Google as a software engineer, data scientist and manager working on everything from ML-based advertising products to highly scalable distributed systems (four years in Silicon Valley). She spent the last 6 years working on AI strategy: alternating between building her own data and AI teams and strategy consulting on how to integrate data and AI into companies. In her last corporate job, she built the software and AI team for the electrical battery startup, Northvolt. She is the founder of Women in Data Science - Sweden, a community of $700+$ women in the field of data science, machine learning, AI and data analytics.

Sandor Albrecht, PhD, Ecosystem Builder, RISE Research Institutes of Sweden \& WALP. Sandor is a community builder and change driver. $\mathrm{He}$ is passionate about innovation and technology incubation. Currently, he is at the Knut and Alice Wallenberg Foundation and RISE Computer Science, working with people that explore new ways of connecting human beings, industries and technologies, all in the pursuit of making it more secure and enjoyable to work and live in a sustainable world. He worked at Ericsson for twenty years in Hungary and Sweden as a leader in product development and corporate research. He was the founder and head of Ericsson Garage, Ericsson's global innovation and incubation platform. He received his Master of Science in Electrical Engineering from Budapest University of Technology and Economics in 1993, and his PhD from the same institution in 2004. He also holds a Master of Applied Science from the University of British Columbia in Canada and a Master of Business Administration from Central European University Business School, Budapest, Hungary.

Daniel Gillblad, RISE - Research Institutes of Sweden and AI Sweden. Daniel is Director of AI Research at RISE, Research Institutes of Sweden and co-director for Scientific Vision of AI Sweden. He has a background in AI, machine learning, data analytics and their practical applications, and has for many years been working with digital- and research strategies in industry and academia. He holds a PhD in Machine Learning and a MSc in Electrical Engineering, both from KTH, Royal Institute of Technology in Stockholm, and has lead research projects, groups and laboratories for almost 15 years. Daniel is an appointed member of the Swedish government advisory board on Digitalization, and has initiated, co-ordinated and co-edited the Swedish AI agenda. 